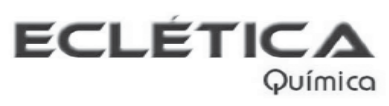

www.scielo.br/eq

Volume 29, número 2, 2004

\title{
Determination of Copper, Iron, Nickel and Zinc in fuel kerosene by FAAS after adsorption and pre-concentration on 2-aminothiazole-modified silica gel
}

\author{
P. S. Roldan ${ }^{1,2}$, I. L. Alcântara ${ }^{1}$, J. C. Rocha ${ }^{1}$, C. C. F. Padilha ${ }^{3}$, P. M. Padilha ${ }^{4}$ \\ ${ }^{1}$ Instituto de Química, Departamento de Química Analítica, UNESP, CP 355, 14800-900 Araraquara,SP, BRAZIL \\ ${ }^{2}$ Centro de Energia Nuclear na Agricultura-USP, 13416-000, Piracicaba, SP,BRAZIL \\ ${ }^{3}$ Instituto de Biociências, Departamento de Física e Biofísica, UNESP, CP 510, 18618-000, Botucatu, SP, BRAZIL \\ ${ }^{4}$ Instituto de Biociências, Departamento de Química e Bioquímica, UNESP, CP 510, 18618-000, Botucatu, SP, BRAZIL \\ E-mail: padilha@ibb.unesp.br or psroldan@cena.usp.br
}

\begin{abstract}
Silica gel chemically modified with 2-Aminotiazole groups, abbreviated as SiAT, was used for preconcentration of copper, zinc, nickel and iron from kerosene, normally used as a engine fuel for airplanes. Surface characteristics and surface area of the silica gel were obtained before and after chemical modification using FT-IR, Kjeldhal and surface area analysis (B.E.T.). The retention and recovery of the analyte elements were studied by applying batch and column techniques. The experimental parameters, such as shaking time in batch technique, flow rate and concentration of the eluent (HCl0.25-2.00 $\mathrm{mol} \mathrm{L}^{-1}$ ) and the amount of silica, on retention and elution, have been investigated. Detection limits of the method for copper, iron, nickel and zinc are $0.77,2.92,1.73$ and $0.097 \mathrm{mg} \mathrm{L}^{-1}$, respectively. The sorption-desorption of the studied metal ions made possible the development of a preconcentration method for metal ions at trace level in kerosene using flame AAS for their quantification.
\end{abstract}

Keywords: preconcentration; modified silica gel; metal ions; fuel kerosene; FAAS determination.

\section{Introduction}

The presence of trace metals in fuels, unless they are added purposely, is usually undesirable, as they may be responsible for the decomposition and poor performance of the fuel, leading to corrosion of the motor and formation of precipitates. Some metals are natural constituents of the crude oil, others can be introduced into the kerosene as contaminants, e.g. through contact with refining and distilling equipment, or during storage and transporte.[2-5, 28]

Volatile elements present in fuels are released to the environment upon combustion and may cause environmental pollution.[14]
Metallic elements are normally present only in very low concentration in kerosene, requiring very sensitive techniques or preconcentration for their determination.[26]

Despite the selectivity and sensitivity of analytical techniques such as atomic absorption spectrometry (AAS), there is a crucial need for the preconcentration of trace elements before their analysis due to their frequent low concentrations in numerous samples (especially water samples). Additionally, since high levels of non-toxic components usually accompany analytes, a cleanup step is often required. Liquid-liquid extraction is a classical method for preconcentrating metal ions and/or matrix removal.[32] Solid phase 
extraction (SPE) is another approach that offers a number of important benefits. It reduces solvent usage and exposure, disposal costs and extraction time for sample preparation. Solid phase extraction has some advantages over liquid-liquid extraction such as a higher preconcentration factor, better efficiency, greater reproducibility and greater simplicity in handling and transfer. Consequently, in recent years SPE has been successfully used for the separation and sensitive determination of metal ions, mainly in water samples. great potential of this technique for speciation studies.[8]

Different procedures are found in the literature for the determination of metals in petroleum derivatives. Atomic absorption spectrometry is extensively used, although the direct introduction of petroleum products may cause flames to become excessively fuel rich and unstable.

Many methods of preconcentration of metal ions from solutions have been described. Of particular interest are those which involve inorganic solid surfaces modified with chelating groups and so have advantage of selectivity.[21, 22] Preconcentration methods can removal of some interferents which may be present in the sample solution, can considerably improve the obtained results extending the limit of detection to lower concentration levels.[9, 15]

Surfaces of inorganic solids have been modified with organofunctional groups for adsorption and preconcentration of metal ions from solutions.[11, 12]

Silica gel is an amorphous inorganic polymer composed of internal siloxano groups (Si$\mathrm{O}-\mathrm{Si}$ ), and with silanol groups $(\mathrm{Si}-\mathrm{OH})$ distributed on the surface.[1,17] The active hydrogen atom of the silanol groups of silica gel has the ability to react with agents containing organosilyl functions, to give some organic nature to the precursor inorganic support.[6, 31]

The accurate determination of trace metals in petroleum products is of significant importance concerning their further utilization. It is well known that some metals catalyze oxidative reactions in hydrocarbon mixtures, degrading their thermal stability and impairing their use as fuel. Only low concentrations of metals can be tolerated before the fuel stability degrades to an undesirable extent. Metals in petroleum products may also cause catalyst poisoning.[4, $16,30,33]$

A relevant goal for the modification of the silica surface is to establish experimental conditions to anchor molecules which can then extract traces of undesired cations dispersed into the pure solvent.[23]

The present paper describes the preparation of silica gel chemically modified with 2-aminothiazole (SiAT) to produce an efficient collector for separation and determination of metal ions dispersed into the kerosene fuel by FAAS.

\section{Experimental}

\section{Reagents}

The stock metal ions solutions were prepared by dissolving the reagent grade chlorides (Merck) in ethanol (Mallinckrodt). Stock standard solutions of copper, zinc, nickel and iron at a concentration of $1000 \mathrm{mg} \mathrm{dm}^{-3}$ were obtained from Merck. Silica gel (35-70 mesh) were obtained from Merck. Water was distilled and de-ionized with a Milli-Q system (Millipore Corp.). The materials and vessels used for trace analysis were kept in $10 \%$ nitric acid at least 24 hours and subsequently four times in de-ionized water. Hydrochloric and nitric acids used were suprapur from Merck.

\section{Organofunctionalization of silica gel[18, 25]}

Silica gel 60 MERCK (35-70 mesh) was activated at $420 \mathrm{~K}$ under vacuum $\left(10^{-3}\right.$ Torr, ca. $0,133 \mathrm{~Pa}$ ). This silica (50 g) were refluxed with N,N-Dimethylformamide (Merck) $\left(135 \mathrm{~cm}^{3}\right)$, $\mathrm{POCl}_{3}$ (Merck) $\left(15 \mathrm{~cm}^{3}\right.$ ), and the mixture was stirred for $36 \mathrm{~h}$ at $380 \mathrm{~K}$ under nitrogen atmosphere. The resulting modified silica (reaction 1) was immersed again in pure $\mathrm{N}, \mathrm{N}$ Dimethylformamide $\left(135 \mathrm{~cm}^{3}\right)$ and 2Aminotiazole (36 g) was added. The mixture was stirred for $36 \mathrm{~h}$ at $380 \mathrm{~K}$ under nitrogen atmosphere. The resulting modified silica (reaction 2), named SiAT, was filtered off and washed with ethanol and dried in vacuum at room temperature. The reactions involved in the preparations of SiAT are show below. 


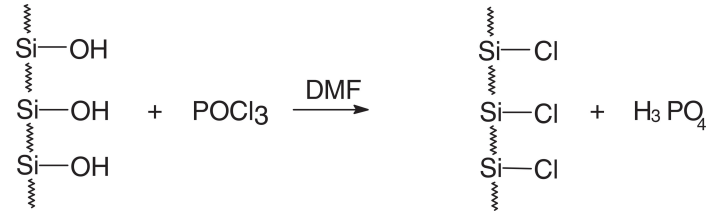

Reaction 1- Chlorination reaction.

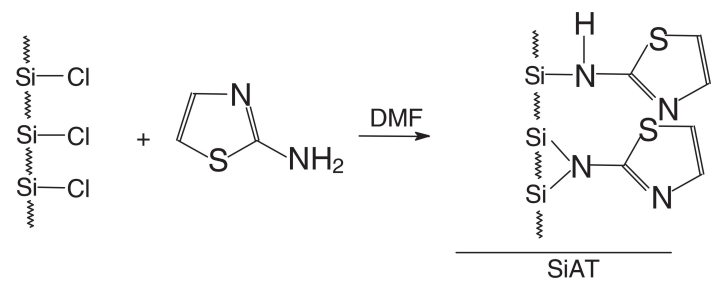

Reaction 2- Immobilization of 2-Aminothiazole groups.

\section{Characterization}

Diffuse reflectance infrared Fourier Transform (DRIFT) spectra were obtained with a Nicolet spectrometer model Nexus 670 with Smart Collector, in Transmittance units, with $3.5 \mathrm{mg}$ of material mixed with $500 \mathrm{mg}$ of $\mathrm{KBr} .[13,22]$

The specific surface area was determined by the B.E.T. method [7] on a Micromeritics ASAP 2010 equipment of Micromeritics Instrument Corporation.

The quantity of 2-aminothiazole groups attached to the silica gel surface was determined by a nitrogen analysis, using a SHIMADZU EA2218 CHNS-O elemental analyzer.

\section{Isotherms of adsorption}

The adsorption capacity of SiAT was determined at $298 \mathrm{~K}$ using the batch technique.[18, 25] In $50 \mathrm{~cm}^{3}$ of ethanol solutions of the metal ions (concentrations between $2 \times 10^{-4}$ and $5 \times 10^{-3} \mathrm{~mol}$ $\mathrm{dm}^{-3}$ ), about $100 \mathrm{mg}$ of SiAT were added and the resulting mixture shaken for $10 \mathrm{~min}$. The solid phase was separated by centrifugation and the metal ion determined in the supernatant solution by complexometric titration.[27]

Pre-concentration of the metal ions in ethanol solutions [25]

This study was carried out using a $8 \mathrm{~cm}$ length and $0.6 \mathrm{~cm}$ inner diameter glass column packed with $1 \mathrm{~g}$ of SiAT (with $5 \mathrm{~cm}$ packing height). Initially, the column was washed with ethanol and then $50 \mathrm{~cm}^{3}$ of 38, 40, 35 and 52 ìg $\mathrm{dm}^{-3}$ of $\mathrm{Cu}(\mathrm{II}), \mathrm{Fe}(\mathrm{III}), \mathrm{Ni}(\mathrm{II})$ and $\mathrm{Zn}(\mathrm{II})$ ethanol solutions, respectively, were percolated through the column with a flow rate of $1.5 \mathrm{~cm}^{3} \mathrm{~min}^{-1}$. The column was washed with $25 \mathrm{~cm}^{3}$ of ethanol, 10 $\mathrm{cm}^{3}$ of de-ionized water and then the metal was eluted with $5 \mathrm{~cm}^{3} \mathrm{HCl}$ solution $(\mathrm{HCl}$ Concentrations $=0.25,0.50,1.00$ and $2.00 \mathrm{~mol}$ $\left.\mathrm{dm}^{-3}\right)$. All fractions obtained during the elution stage were gathered separately and analysed by Flame AAS. The concentrations of the metal ions were also determined by GFAAS (Graphite Furnace Absorption Atomic Spectrometry) to compare with the results obtained using the preconcentration step.

\section{Determination by FAAS}

The concentrations of metal ions gathered from the SiAT column were determined by FAAS according to the standard guidelines of the manufacturers (Spectrometer: SHIMADZU AA6800) [20], choosing resonance lines for the metals and deuterium-arc lamp background correction. For the calibration, synthetic standard solutions containing on $1.0 \mathrm{~mol} \mathrm{dm}^{-3} \mathrm{HCl}$ comparable to the samples, were used.

\section{Results and discussion}

\section{Characterization of the material}

The chemical analysis of nitrogen in SiAT showed a contend of $1.24 \pm 0.07 \mathrm{mmol}$ g- 1 of 2aminothiazole groups bounded to the silica gel surface. The specific surface area was found to be $354 \pm 0.6 \mathrm{~m}^{2} \mathrm{~g}^{-1}$. The decrease showed by the SiAT specific surface area were attributed to the covalently bound between siliceous groups and 2Aminothiazole groups, recovering the active sites and forming a impediment on the surface of silica gel. [18, 25]

Diffuse reflectance infrared Fourier Transform spectra (DRIFT) were collected on a Nicolet spectrometer model Nexus 670 with Smart Collector purged with dried air, with a resolution of $8 \mathrm{~cm}^{-1}$ by accumulating 200 scans. Infrared spectra of different silica samples in the 4000 to $500 \mathrm{~cm}^{-1}$ range were obtained by the dilution at $99,3 \%$ in a $\mathrm{KBr}$ matrix (Aldrich, purity 99\%) previously dehydrated at $100{ }^{\circ} \mathrm{C}$ during 24 hours. The background spectrum is recorded with a pure 
$\mathrm{KBr}$. A standard matrix is made with pure silica gel diluted at 99,3 \% in $\mathrm{KBr}$.

The infrared for pure silica (PS) and SiAT are show in figure 1 . A small difference is observed in relation to the number and intensities of the bands in comparing activated silica and the other modified silica (SiAT). This same behavior was previously observed for the other anchored processes. [24,29]

The infrared spectra shown in figure 1 confirm the presence of 2-aminothiazole groups bound to the silica surface. The absorption band observed at $2784 \mathrm{~cm}^{-1}$ is due to the $\mathrm{C}-\mathrm{H}$ stretching of aromatic olefins. The other two bands of interest are observed at 1471 and $1395 \mathrm{~cm}^{-1}$, what can be assigned to the äC=N and äN-H, both dislocated from low frequencies due to the äSi-O remaining of silica gel what strongly absorption at $1630 \mathrm{~cm}^{-}$ ${ }^{1} .[18,25]$

Between 2500 and $3800 \mathrm{~cm}^{-1}$, the spectra exhibit a broad and featureless band corresponding to the stretching vibrations of the surface silanols $\mathrm{Si}-\mathrm{OH}$ perturbed by hydrogen bonding either intramolecularly or with adsorbed water.

Below $1500 \mathrm{~cm}^{-1}$, the spectra exhibit a broad and intense band around $1100 \mathrm{~cm}^{-1}$, characteristic of the ant symmetric stretching vibration of the $\mathrm{Si}-\mathrm{O}-\mathrm{Si}$, and a less intense band around $900 \mathrm{~cm}^{-1}$ (Si-O-Si symmetric stretching vibrations).

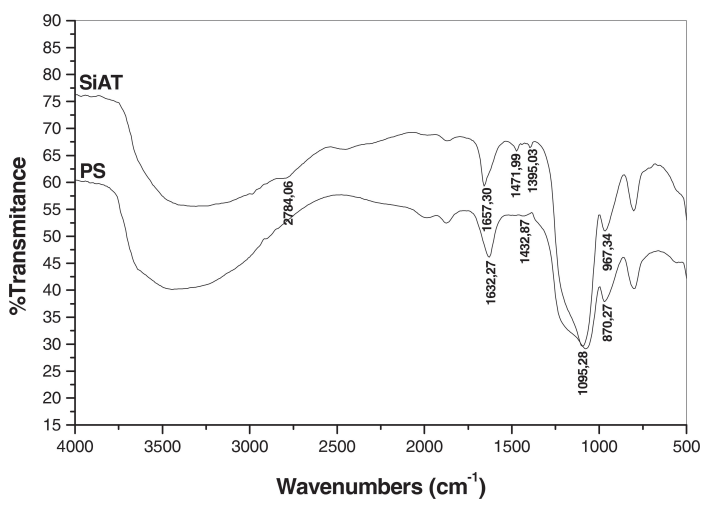

Figure 1- Infrared spectra of pure silica (PS) and modified silica (SiAT).

\section{Batch and Column method}

\section{Equilibrium time}

The time required for this reaction to achieve the equilibrium condition was previously determined immersing $100 \mathrm{mg}$ of SiAT in $50 \mathrm{~cm}^{3}$ of $5 \times 10^{-3} \mathrm{~mol} \mathrm{dm}^{-3}$ of the metal solution and shaken. At different time intervals, an aliquot of the supernatant solution was separated and the metal ion analysed by complexometric titration using EDTA as the titrant. [27] The results obtained are show in the figure 2 .

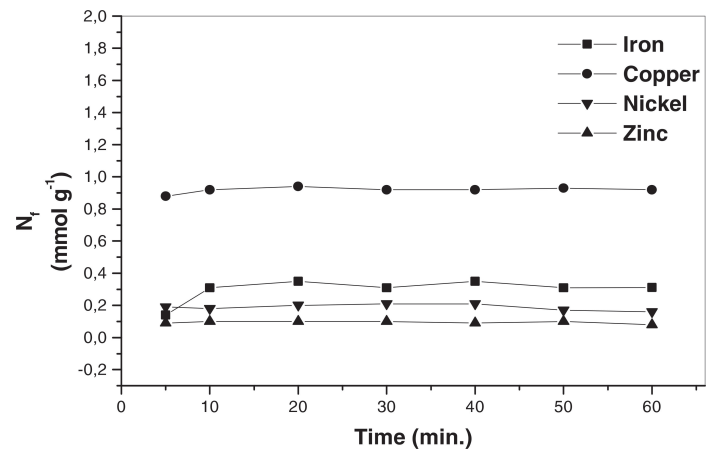

Figure 2 - Time required to equilibrium between metal ions and SiAT in solution with shaking.

The quantity of the adsorbed metal per unit mass of the adsorbent, $\mathrm{N}_{\mathrm{f}}$, was calculated applying the equation:

$$
N_{f}=\frac{\left(n_{i}-n_{s}\right)}{m_{S i A T}}
$$

Equation 1

Where: $n_{i}$ represents the initial mole number of the metal ion in the solution phase, $n_{s}$ the mole number of the metal ion in equilibrium with the solid phase and $m_{\text {SiAT }}$ is the mass of the adsorbent.

The kinetics of the adsorbent-metal interaction are of considerable importance if the adsorbent is to be used in a dynamic system such as a packed column and a flowing stream. If the complex is not sufficiently rapid for certain metals, then their concentration on a packed column is unlikely owing to the short contact time between the resin and the solution. In those cases a batch extraction with a large excess of adsorbent should be conducted over an extended period. In all cases 
the kinetics are rapid and with around $10 \mathrm{~min}$. of interaction between metal ions and SiAT in ethanol solution, the state of equilibrium was established. At least, more than $95 \%$ of ions were extracted within 5 min of interaction with the modified adsorbent, except for iron, where the equilibrium was established between 10-15 minutes.

\section{Adsorption capacity of the SiAT}

The adsorption capacity of the chemically modified solid support is an important factor to determine how much adsorbent is required to quantitatively remove a specific metal ion from the solution by column and flow system method.

The adsorption capacity of SiAT was determined at $298 \mathrm{~K}$ using the batch technique. In $100 \mathrm{~mL}$ of ethanol solutions of the metal ions (concentrations between $2.0 \times 10^{-4}$ and $5 \times 10^{-3} \mathrm{~mol}$ $\mathrm{dm}^{-3}$ ), about $100 \mathrm{mg}$ of SiAT were added and the resulting mixture shaken for $10 \mathrm{~min}$. The solid phase was separated by centrifugation and the metal ion determined in the supernatant solution by complexometric titration using EDTA. The results are show in the figure 3.

Comparing the number of active sites (1.24 $\left.\mathrm{mmol} \mathrm{g}^{-1}\right)$, and the number of metal ions bonded with the SiAT $\left(1.20 \mathrm{mmol} \mathrm{g}^{-1}\right)$, the interaction between metal ions in solution and SiAT was done only by chemisorptions.

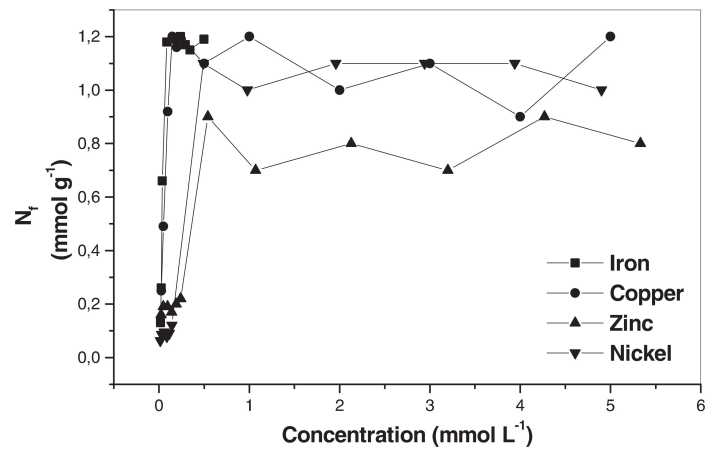

Figure 3 - Capacity of the SiAT: copper and iron- $1.20 \mathrm{mmol}$ $\mathrm{g}^{-1}$, zinc- $0.90 \mathrm{mmol} \mathrm{g}^{-1}$ and nickel- $1.10 \mathrm{mmol} \mathrm{g}^{-1}$.

\section{Analytical performance of the method}

The analytical performance of the method can be show for the results from FAAS measurements. This study was carried out using a $8 \mathrm{~cm}$ length and $0.6 \mathrm{~cm}$ inner diameter glass column packed with $1 \mathrm{~g}$ of SiAT. Initially, the column was washed with ethanol and then $50 \mathrm{~cm}^{3}$ of $38,40,35$ and $52 \mathrm{mg} \mathrm{dm}^{-3}$ of $\mathrm{Cu}(\mathrm{II}), \mathrm{Fe}(\mathrm{III})$, $\mathrm{Ni}(\mathrm{II})$ and $\mathrm{Zn}(\mathrm{II})$ ethanol solutions, respectively, were percolated through the column with a flow rate of $1.5 \mathrm{~cm}^{3} \mathrm{~min}^{-1}$, that corresponding the time required to complete interaction between metal ions and SiAT column. Above $1.5 \mathrm{~cm}^{3} \mathrm{~min}^{-1}$ the analytical signal decrease owing to the short residence time of the solution, which results in a incomplete retention of metal ions. The column was washed with $50 \mathrm{~mL}$ of ethanol and then the metal was eluted with $5 \mathrm{~cm}^{3} \mathrm{HCl}$ solution $([\mathrm{HCl}]=$ $0.25,0.50,1.00$ and $2.00 \mathrm{~mol} \mathrm{dm}^{-3}$ ). All fractions obtained during the elution stage were gathered separately and analysed by Flame AAS. The recoveries of analytes from $50 \mathrm{~cm}^{3}$ of ethanol solutions with specific metal concentrations were higher than 95\%, thus confirming the accuracy of the procedure (table 2).

\begin{tabular}{|c|c|c|}
\hline Metal & Added $\left(\mu \mathrm{g} \mathrm{dm}^{-3}\right)$ & Recovery (\%) \\
\hline $\mathrm{Cu}$ & 38 & $97 \pm 1.7$ \\
\hline $\mathrm{Fe}$ & 40 & $98 \pm 1.5$ \\
\hline $\mathrm{Zn}$ & 52 & $97 \pm 1.6$ \\
\hline $\mathrm{Ni}$ & 35 & $100.4 \pm 1.3$ \\
\hline
\end{tabular}

Table 2 - Recovery efficiencies of $\mathrm{Cu}, \mathrm{Fe}, \mathrm{Ni}$ and $\mathrm{Zn}$ from ethanol standard solutions. Eluent: $\mathrm{HCl}-1 \mathrm{~mol} \mathrm{dm}^{3}{ }^{3}$

The recovery experiment for each metal ion from a synthetic solution served as basis for a rapid method for preconcentration and determination of copper, iron, nickel and zinc in kerosene fuel. Table 3 shows the concentrations of the metal ions in fuel kerosene samples produced in three different industries. The detection limits calculated in this conditions were 0.77, 2.92, 1.73 and $0.097 \mathrm{mg} \mathrm{dm}^{-3}$ for $\mathrm{Cu}(\mathrm{II})$, $\mathrm{Fe}(\mathrm{III}), \mathrm{Ni}(\mathrm{II})$ and $\mathrm{Zn}(\mathrm{II})$, respectively. The concentrations of $\mathrm{Cu}(\mathrm{II}), \mathrm{Fe}(\mathrm{III}), \mathrm{Ni}(\mathrm{II})$ and $\mathrm{Zn}(\mathrm{II})$ are low in the analysed samples, however are above of detection limits determined for the proposed preconcentration method. These results are in accordance with results obtained with other preconcentration method, $[10,19]$ and also are in accordance with results obtained by direct determinations with GFAAS. 


\begin{tabular}{|c|c|c|c|c|c|c|c|c|}
\hline \multirow[t]{3}{*}{ *Sample } & \multicolumn{8}{|c|}{ Concentration of metal ions $\left(\mu \mathrm{g} \mathrm{L}^{-1}\right)$} \\
\hline & \multicolumn{2}{|c|}{ Copper } & \multicolumn{2}{|c|}{ Iron } & \multicolumn{2}{|c|}{ Nickel } & \multicolumn{2}{|c|}{ Zinc } \\
\hline & $\begin{array}{l}\text { FAAS- } \\
\text { SiAT }\end{array}$ & GFAAS & $\begin{array}{c}\text { FAAS- } \\
\text { SiAT }\end{array}$ & GFAAS & $\begin{array}{l}\text { FAAS- } \\
\text { SiAT }\end{array}$ & GFAAS & $\begin{array}{c}\text { FAAS- } \\
\text { SiAT }\end{array}$ & GFAAS \\
\hline 1 & $8.0 \pm 0.4$ & $7.0 \pm 0.3$ & $\begin{array}{c}11.0 \pm 0 \\
4\end{array}$ & $\begin{array}{c}10.0 \pm 0 \\
3\end{array}$ & $3.0 \pm 0.1$ & $4.0 \pm 0.1$ & $8.0 \pm 0.3$ & $9.0 \pm 0.4$ \\
\hline 2 & $6.0 \pm 0.2$ & $5.0 \pm 0.3$ & $9.0 \pm 0.3$ & $8.0 \pm 0.3$ & $4.0 \pm 0.2$ & $4.0 \pm 0.1$ & $6.0 \pm 0.2$ & $5.0 \pm 0.4$ \\
\hline 3 & $7.4 \pm 0.3$ & $7.6 \pm 0.4$ & $9.2 \pm 0.3$ & $8.8 \pm 0.2$ & $5.3 \pm 0.1$ & $4.9 \pm 0.1$ & $7.2 \pm 0.3$ & $6.9 \pm 0.3$ \\
\hline
\end{tabular}

Table 3 - Determination of copper, iron, nickel and zinc in different kerosene fuel samples by FAAS with preconcentration on a column packed with SiAT and direct determination by GFAAS.

*Fuel kerosene samples collected from different industries: 1- Petrobrás, 2- Neiva (manufacture of airplanes), 3- Texaco.

\section{Conclusions}

2-aminothiazole groups attached to a silica gel surface can readily be used to adsorb metal ions from ethanol solution and fuel kerosene. Its relatively high chemical stability in kerosene, and the velocity with which the metal ions are adsorbed, turns this material potentially useful for analytical purposes. The complexant 2aminothiazole can be immobilized onto silica gel by use of a simple method. The collector SiAT obtained this way shows a high selectivity and capacity towards heavy metal ions.

The capacity of the SiAT is sufficiently high to preconcentrate more than one metal ion simultaneously.

The equilibration is fast as $97-100 \%$ metal ions are sorbed within 5 min. of interaction. In addition, high enrichment factors $(\mathrm{F}=10)$ and low detection limits are obtained.

\section{Acknowledgments}

The authors thank the FAPESP (Projects 99/12916-0), FUNDIBIO, FINEP, ANP for financial support and CAPES for a fellowships to P. S. Roldan and I. L. Alcântara.

P. S. Roldan, I. L. Alcântara, J. C. Rocha, C. C. F. Padilha, P. M. Padilha. Determinação de cobre, ferro, níquel e zinco em querosene combustível após adsorção e preconcentração sobre sílica gel modificada com grupos 2-aminotiazol.

Resumo: Sílica gel quimicamente modificada com grupos 2-aminotiazol (SiAT), foi utilizada na preconcentração traços de cobre, ferro, níquel e zinco em meio não aquoso. O material organofuncionalizado foi caracterizado por determinação da área superficial, análise elementar de nitrogênio e FTIR. A capacidade de retenção e recuperação dos íons metálicos foi estudada utilizandose o método em batelada e por coluna. Os parâmetros experimentais, como tempo de contato dinâmico na técnica em batelada, vazão e concentração do eluente, massa de adsorvente (SiAT) na técnica em coluna, foram investigados. O limite de detecção determinado para o método de pré-concentração foi de $0,77,2,92,1,73$ e $0,097 \mathrm{mg} \mathrm{L}^{-1}$, respectivamente para cobre, ferro, níquel e zinco. A sorção-desorção quantitativa dos íons metálicos estudados, possibilitou a aplicação do método na préconcentração de 
traços de cobre, ferro, níquel e zinco em amostras de querosene combustível, para posterior quantificação por FAAS.

Palavras-chave: pré-concentração; silica-gel modificada, ions metálicos; querosene; determinação por FAAS.

\section{References}

[1] C. Airoldi, R. F. Farias, Química Nova 23 (4) (2000) 496.

[2] H.M. Al-Swaidan, Anal. Lett. 26 (1993) 141.

[3] H.M. Al-Swaidan, At. Spectrosc. 14 (1993)170.

[4] R.Q. Aucelio, A.J. Curtius, J. Anal. At. Spectrom. 17 (2002) 242.

[5] G. J. Antos, A.M. Aitani, J.M. Parrera, Sci. and Tech. 1995.

[6] L. A. Belyakova, A. M. Varvarin, Coll. and Surf. A: Physicochemical and Engineering Aspects 154 (1999) 285.

[7] S. Brunauer, P. H. Emmet, E. Teller, J. American Chem. Soc.,60 (1938) 309.

[8] V. Camel, Spectroc. Acta Part B 58 (2003) 1177.

[9] N. L. Dias Filho, Y. Gushiken, W. L. Polito, J. C. Moreira, E. O. Ehirim, Talanta 42 (1995) 1031. [10] D. K. Tanaka, S. Wolynec, Proc. of IXth National Seminar on Corrosion, Rio de Janeiro, dec. 8-12, 1982.

[11] C Ekinci, Ü. Köklü, Spectroc. Acta Part B 55 (2000) 1491.

[12] S. Faramawy, A. M. El-Fadly, A. W. El-

Naggar, A. M. Youssef, Surf. and Coat. Tech. 90 (1997) 53.

[13] C. Fulcker, Anal. Chim. Acta 129 (1981) 29.

[14] K. E. Giller, E. Witter, S. P. Mcgrath, Soil Biol. Biochem. 30(10/11) (1998)1389,.

[15] L. T. Kubota, J. C. Moreira, Y. Gushiken, Analyst 114 (1989) 1385.

[16] D. M. Little, in: Catalytic Reforming, 1985. [17] W. X. Ma, F. Liu, K. A. Li, W. Chen, S. Y. Tong, Anal. Chim. Acta 416 (2000) 191.

[18] F. V. Moraes, I. L. Alcântara, P. S. Roldan, G. R. Castro, M. A. L. Margionte, P. M. Padilha, Ecl. Quím., v.28(1) (2003) 9.

[19] N. L. D. K Tanaka, S. Wolynec, S. Fairbanks, F. B. P. Pinto VIIIth National Seminar on Corrosion, Rio de Janeiro, dec. 5-10, 1981.

[20] Operation manual atomic absorption spectrophotometer AA-6800, Shimadzu [s.1:s.n.], 2000.

[21] P. M. Padilha, L. A. Gomes, C. C. F. Padilha, J. C. Moreira, N. L. Dias Filho, Anal. Lett. 32 (1999)1807.

[22] A. G. S. Prado, C. Airoldi, Pest. Manag. Sci. 56 (2000) 419.

[23] G. S. A. Prado, C. Airoldi, Anal. Chim. Acta 432 (2000) 201.

[24] A. G. S. Prado, C. Airoldi, J. of Coll. and Interf. Sci.,236 (2001) 161.

[25] P. S. Roldan, I. L. Alcântara, G. R. Castro, J. C. Rocha, C. C. F. Padilha, P. M. Padilha, Anal. and Bio. Chem. 375 (2003) 574.

[26] T. D. Saint'pierre, L. F. Dias, D. Pozebon, R. Q. Aucelio, A. J. Curtius, B. Welz, Spectroc. Acta Part B 57 (2002) 1991.

[27] G. Schwarzenback, H. A. Flaschka, Complexometric titrations, 1969.

[28] I.A. Silva, R.C. Campos, A.J. Curtius, S.M. Sella, J. Anal. At. Spectrom. 8 (1993) 749.

[29] G. Socrates, John Wiley \& Sons, 1996.

[30] V. Sychra, I. Lang, G. Sebor, Prog. Anal. Atom. Spect. 4 (1981) 341.

[31] E. F. Vasant, P. V. D. Voort, K. C. Vrancken, Elsevier, 93, 1995.

[32] G. T. Wei, Z. Yang, C. J. Chen, Anal. Chim. Acta, 488 (2003) 183.

[33] H. Walker, J. H. Runnels, D. Merryfield, Anal. Chim. Acta 48 (1976) 2056. 